\title{
Unusual Hanging- A Case Report
}

\author{
Ajitesh $\mathrm{Pal}^{*}$ and HK Pratihari \\ Tripura State Forensic Science Laboratory, Agartala
}

*Corresponding author: Ajitesh Pal, Tripura State Forensic Science Laboratory, Agartala-799015, India, E-mail: ajiteshp@rediffmail.com

Citation: Ajitesh Pal and HK Pratihari (2017) Unusual Hanging- A Case Report. J Forensic Cri Stu 1:101

Article history: Received: 7 January 2017, Accepted: 31 March 2017, Published: 03 April 2017

\begin{abstract}
In stressful life, suicide is very common. There are various methods and techniques to commit suicide in the world. The literature on the subject indicates that hanging is very common method of committing suicide in India. Ligature materials like cotton, jute rope, electric wire, belt, napkin, sari, dhoti, duppatta (dress materials) are being used to meet the requirement. In almost all cases of suicidal hanging, knots are generally present in the noose. In one case of suicidal hanging, a 26-year-old male used a bunch of jute string as ligature material but without a knot. External examination of the body in hanging position from the branch of a tree revealed all the common suicidal symptoms like stretched neck, pale face, protruded tongue, dribbling of saliva from mouth, discharge of seminal fluid along with other features. All the observations are suggestive of a case of suicidal hanging. In addition, post mortem (PM) findings corroborated the observation made at the scene of crime and confirmed the death was due to unusual suicidal hanging.
\end{abstract}

Keywords: Forensic Science; Unusual Hanging Loop; Ligature Material; Noose without Knot; Autopsy Study

\section{Introduction}

Hanging is the preferred method of suicide in most countries in the world [1-4]. People prefer hanging as a quickest and easiest method of suicide due to easy availability of hanging materials and believe it to be surest and painless [5]. A good number of people die each year by suicide adopting various methods in the world. According to WHO (World Health Organization) and research report $[4,6]$ the suicide by hanging is more in men in comparison to women in almost all the countries. Further, violent and highly lethal methods like firearm suicide and hanging are more frequent among men, whereas women often choose poisoning/drowning which are considered to be less violent/lethal [6]. However, data show that means adopted for suicide also vary from country to country [6,7].

Hanging is an ideal method of suicide with an estimated fatality rate of over $70 \%[8,9]$. Asphyxia in hanging results from compression or constriction of the neck structure by a noose or other kind of stricture about the neck tightened by the weight of body. Hanging may be typical or atypical depending on the position of knot in the noose. If the knot of the ligature is present at the nape of the neck, it is classified as typical hanging and the knot of the ligature at any site other than the nape of the neck is atypical hanging [10].

Presence of some form of knot in the noose is observed almost in all suicidal hanging cases. The hanging with a loop (without noose and knot) is rarely reported in literature [11,12]. In the present paper, the authors describe a rare case of an unusual suicidal hanging where multiple turn of jute string in the form of loop was used as ligature material and no knot was present at the neck.

\section{Case report}

A young male age about 26-year got married, a couple of years back. He used to maintain his livelihood from the poor income being an auto-driver and used to pass hard days. His strained family relation also added misery to his life. Finding no other ways and unable to adjust himself, he committed suicide by hanging from the branch of a tree. This fact is also supported by the intelligence feedback collected from the victim's family by the investigating agency. The ligature material was a bunch of jute string used by the deceased in a U-shaped manner around the upper part of the front and sides of the neck and below the chin. The ligature was passing through the side of both the ears. Thus, there was no knot in the noose in such hanging and ligature material was tied with the branch of a tree. Height of the point of attachment of ligature to the branch of tree from the ground was $2.74 \mathrm{~m}$, height of the bottom of the jute coil from the ground was $1.5 \mathrm{~m}$ and height of the deceased was $1.62 \mathrm{~m}$ (Figure 1,2,3 and 4). The feet of the deceased were very close proximity over the ground. 


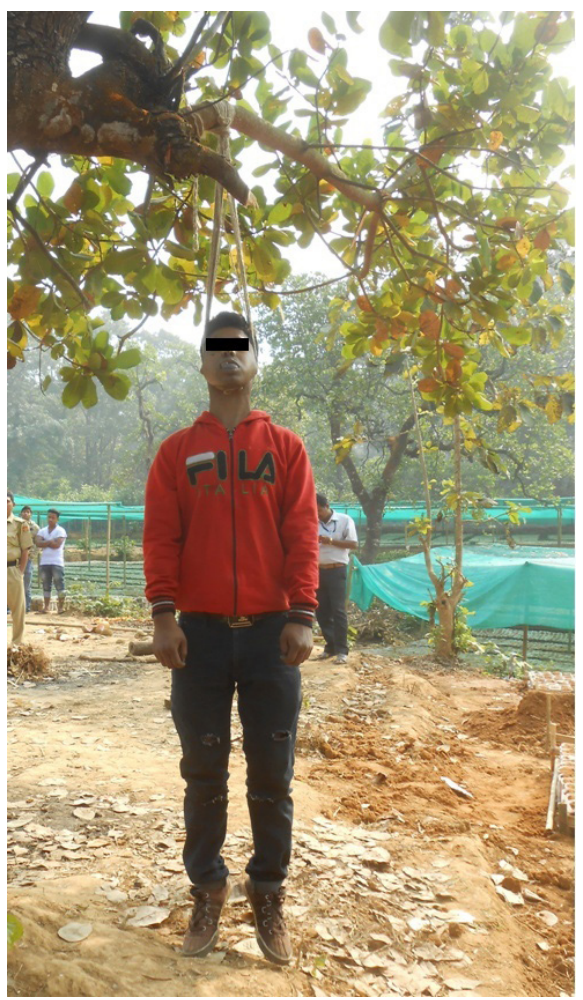

Figure 1: Hanging position of deceased showing the stretched loop with fixed knot

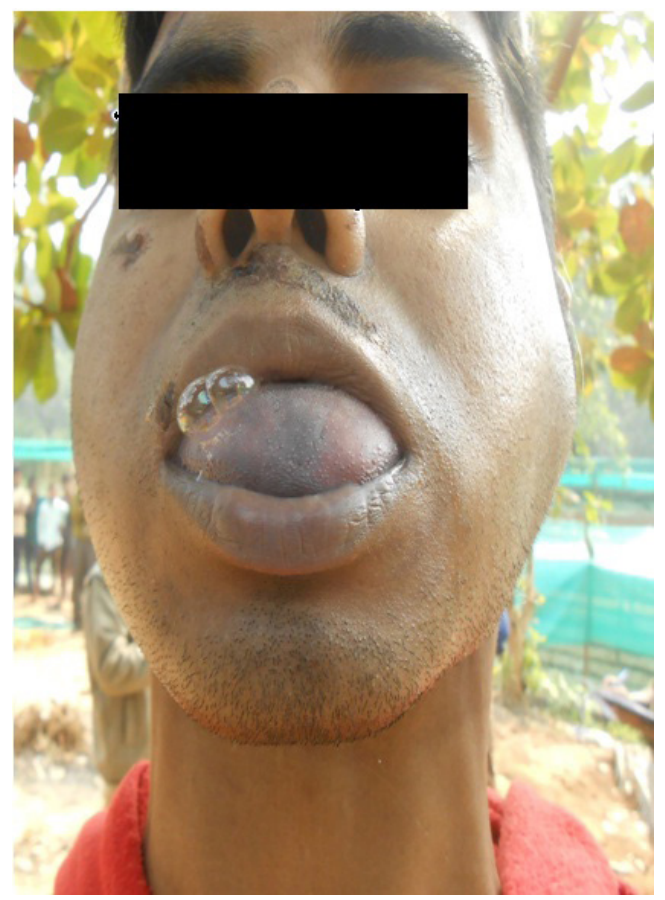

Figure 2: Protruded tongue with dribbling saliva

\section{Autopsy Findings}

The deceased was about 26-year-old, male, $1.62 \mathrm{~m}$ in height, $56 \mathrm{~kg}$ in weight and average built. The facial features were congested, soiled with dry mud, eyes were closed, and mouth was partially opened. The tongue was congested and protruded from between the teeth and lips. One brownish-black, grooved ligature mark of maximum width of $0.02 \mathrm{~m}$ was found present on front and both sides of the neck. The mark was directed obliquely upward towards back of the neck of deceased. Out of total $0.4 \mathrm{~m}$ neck circumference, the ligature mark was found to be absent for around $0.14 \mathrm{~m}$ at backside. Further, ligature mark was situated just touching the tip of left mastoid process, $0.06 \mathrm{~m}$ below the chin, $0.11 \mathrm{~m}$ above the suprasternal notch and $0.02 \mathrm{~m}$ below the tip of right mastoid process. On dissection, the skin and subcutaneous tissues were found white and glistening having no contusions in the layers of muscles of the neck. The hyoid bone, thyroid cartilage and cricoid cartilage were found to be intact. The intima of carotid arteries was also found intact. Few ecchymoses were present along the margins of ligature mark. 


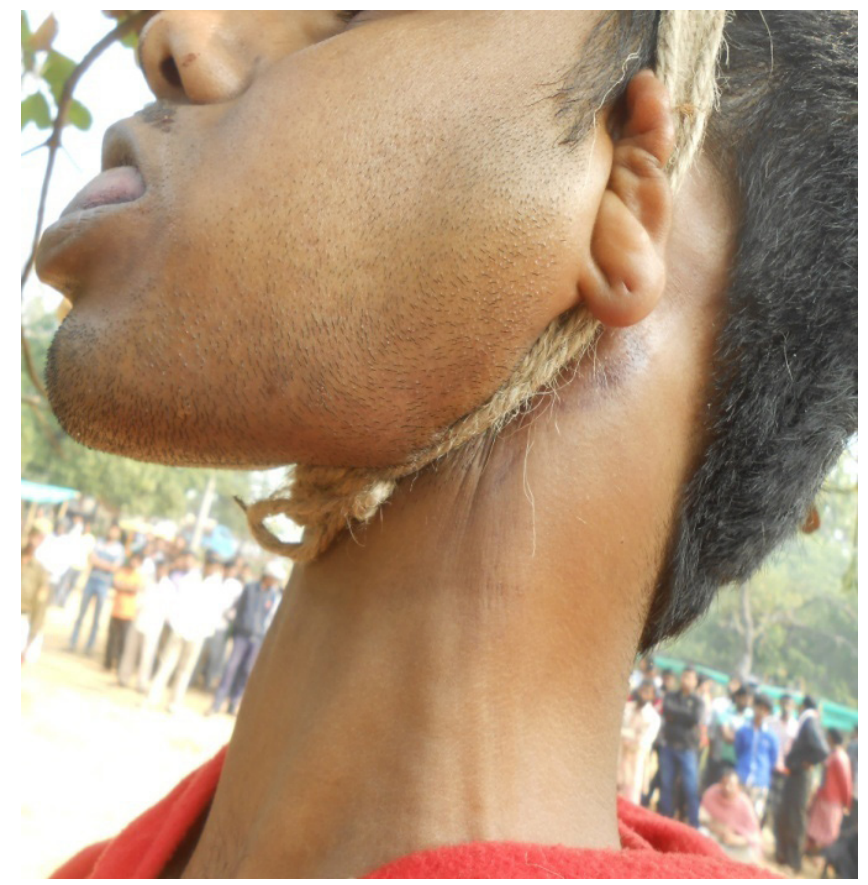

Figure 3: Hanging material (loop) passing through neck and left ear

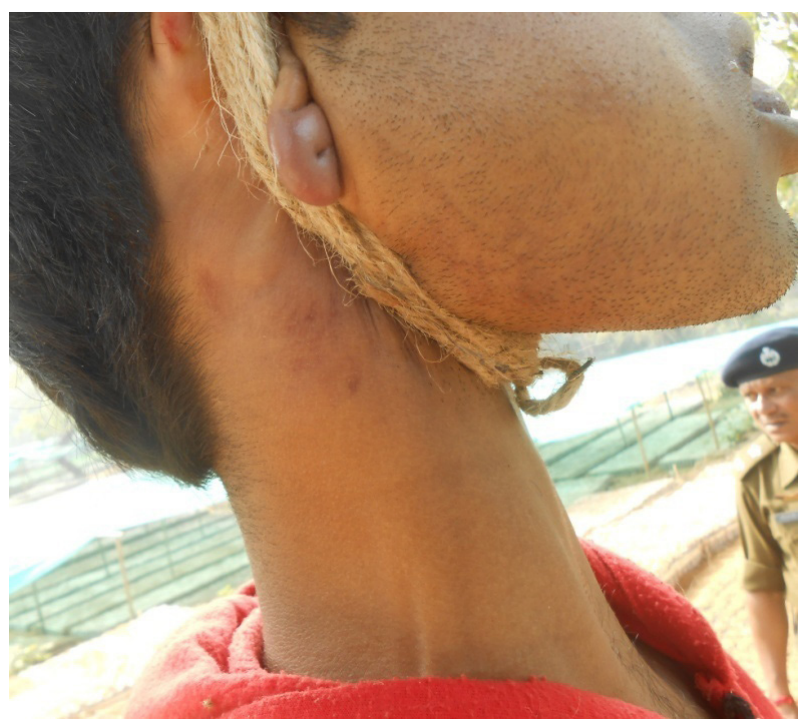

Figure 4: Hanging material (loop) passing through neck and right ear

\section{Results and Discussion}

The examination of crime scene by forensic experts is very much helpful in locating, collecting, and interpreting evidence found at the scene of crime. Such investigation plays an important role in drawing up logical and accurate conclusion. Forensic investigation utilizes scientific methods or techniques to evaluate the physical evidence at scene of crime. The gathered evidence is then examined to determine the information they carry to link and establish the real fact.

In the present case, a team of forensic expert visited the crime spot where a young male person committed suicide by hanging from the branch of a tree. This was an unusual hanging with a simple loop (noose without knot) and suspected to be suspicious. However, on thorough examination of the body in hanging position, many hanging symptoms such as pale face, protruded tongue between teeth and lips, dribbling of saliva from mouth, cyanosis on finger nail beds could be observed. The body was removed from hanging position for inquest and subsequently, an incomplete thick U-shaped ligature compression mark was found in front side of the neck. On both sides, the mark was prominent below the ears and showing evidence of frictional abrasion on the skin. As per PM report, it is known that the weight of the deceased was about $56 \mathrm{~kg}$ and such weight could exert sufficient pressure to produce deep seated ligature mark on the upper part of neck (Figure 5 and 6). The suicide by hanging is also supported by available circumstantial evidence on crime spot. The knot of the jute coil over the branch of tree was tightly fixed. The possibility of accidental hanging could be ruled out since he could climb the tree and fix the knot on the branch by himself. Further, toxicological analysis of the blood and urine including viscera of the deceased could not establish the presence of alcohol and common poison. 


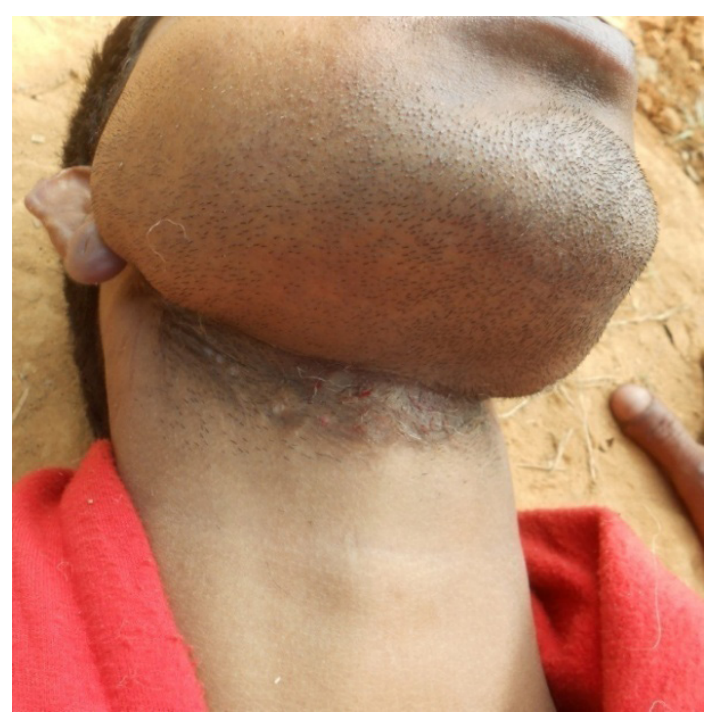

Figure 5: Ligature mark above laryngeal cartilages

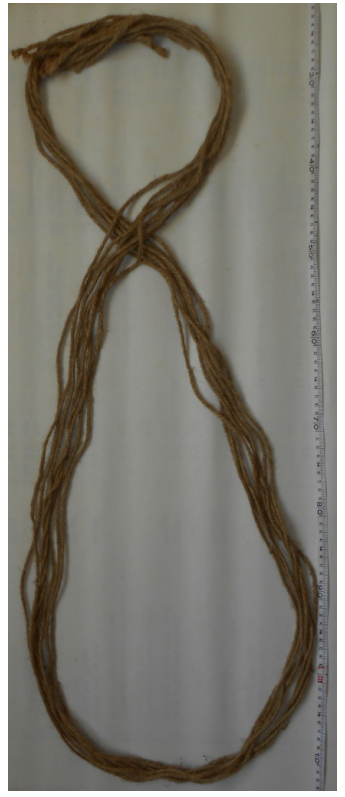

Figure 6: Hanging material after removal

\section{Conclusion}

The crime scene is a treasure of clues and proper examination of spot, collection of physical evidence and their evaluation could help to establish the real fact. Further, the autopsy findings and circumstantial evidence in the present case conclusively suggested suicidal hanging and ruled out the possibility of strangling and homicidal hanging.

\section{References}

1. Suicides in the United Kigdom (2013) Registrations.

2. Erin M, Sullivan MPH, Joseph L. Annest, Thomas R Simon, et al. (2015) Suicide Trends Among Persons Aged 10-24 Years-United States 64. 201-5.

3. Evans, Glen, et al. (2003) The Enclyopedia of Suicide. 2nd ed. New York NY: Facts on File, Inc.

4. Värnik A, Kõlves K, van der Feltz-Cornelis CM, Marusic A, Oskarsson H, et al. (2008) Suicide methods in Europe: a gender-specific analysis of countries participating in the "European Alliance Against Depression" J Epidemiol Community Health 62:545-51.

5. Lucy Biddle, Jenny Donovan, Amanda Owen-Smith, John Potokar, Damien Longson, et al. (2010) Factors influencing the decision to use hanging as a method of suicide: qualitative study. Br J Psychiatry 197: 320-25.

6. Ajdacic-Gross V, Weiss MG, Ring M, Hepp U, Bopp M, et al. (2008) Methods of suicide: international suicide patterns derived from the WHO mortality database. Bulletin of the World Health Organization 86: 726-32.

7. Yip PS, Caine E, Yousuf S, Chang SS, Wu KC, et al. (2012) Means restriction for suicide prevention. Lancet 379: 239-99.

8. Simounet C, Bourgeois M (1992) Suicides and attempted suicides by hanging. Ann Med Psychol (Paris).150: 481-5.

9. Aufderheide TP1, Aprahamian C, Mateer JR, Rudnick E, Manchester EM, et al.(1994) Emergency airway management in hanging victims. Ann Emerg Med. 24: 879-84. 
10. Nandy A (2003) Principles of forensic medicine. $2^{\text {nd }}$ Ed. Calcutta: New central Book Agency 315-43.

11. Kumar V (2007) Hanging without knot in the noose, J Forensic Leg Med. 14: 35-8.

12. Das SK, Chattopadhya S (2009) Hanging or strangling? A case report of suicidal hanging without knot at the neck. J. Indian Acad forensic Med. 31: 373-6. 